ganglionnaires hypertrophiées, encapsulées par du tissu fibrolardacé!' Il s'agit du'ganglion cervical moyen inférieur (G. Petit) et du ganglion cervical inférieur (G. Petit) encore dénommé prépectoral (Leese). A la coupe, le tissu lymphatique est onscrré dans des mailles de tissu fibreux.

L'examen des autres régions ne présentait rien de particulier. Nous avions déjà signalé ailleurs. (Archives de I'Institut Pasteur d'Algérie, t. XXIII, $\mathrm{n}^{0}$ 4) une fibromatose des membres postérieurs. Dans les deux cas; les ganglions lymphatiques ont réagi et ont été trouvés fibromateux; ceci vérifierait la théorie admettant la voie lymphatique pour Ic processus cancérigène. L'origine de cette fibromatose n'est toutefois pas solutionnée.

\title{
Quelques anomalies dentaires chez le Chameau
}

\author{
par A. BOUÉ, vétérinaire lieutenant
}

ЦES anomalies dentaires notées ci-dessous ressortent de l'observalion systémalique de 503 drumadaires adultes abattus à l'abattoir de C.B.

Nous envisagerons d'abord les anomalies des arcades dentaires puis celle's des dents.

\section{I. - ANOMALTES DES ARCADES DENTAIRES.}

Elles affectent l'arcade incisive inférieure; on sait qu'au maxillaire supérieur ne subsistent que les coins. Elles corriespondont à un manque de symćtrie tant par rapport au plan axial que par rapport au plan horizontal.

a) Asymétrie par rapport au plan axial. - Trois cas observés. L'arc alvéolaire normalement parabolique est ici asymétrique; alors qu'un côté est normal, l'autre, moins incurvé, tend vers la ligne droite; les incisives sont de ce fait en position rejetées en arrière. Le décalage des dents influe sur la position des canines et dès prémolaires caniniformes qui ne se correspondent plus. Les incisives en retrait sont plus usées que celles du côté normal. Voir schéma $n^{\circ} 1$.

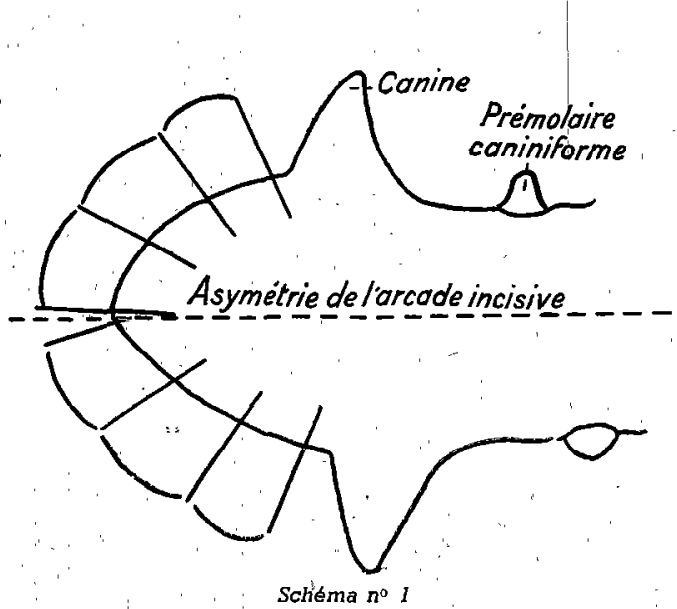

b) Asymétrie par rapport au plan horizontal. L'asymétrie est 'due à une legere torsion de l'extrémité du maxillaire. Si la table dentaire reste horizontale par l'usure, la table comparée de deux incisives homologues n'offre pas une forme identique, les dents'n'ayant pas la même longueur. Deux. cas observés.

\section{II. - ANOMALIES DES DENTS.}

Celles qui intéressent les incisives procèdent $\alpha$ 'une direction et d'une implantation vicieuses; elles sont rares. Les variations numériques, par contre, concernent les prémolaires et les molaires.

a) Anomalie de direction. - Une seule observation constatée sur un coin gauche inférieur. Lia dent présente un mouvement de torsion autour de son axe; redressée, elle ne participe pas à la formation de l'arcade incisive et se dirige à l'intérieur de la bouche. Voir dessin no 2 .

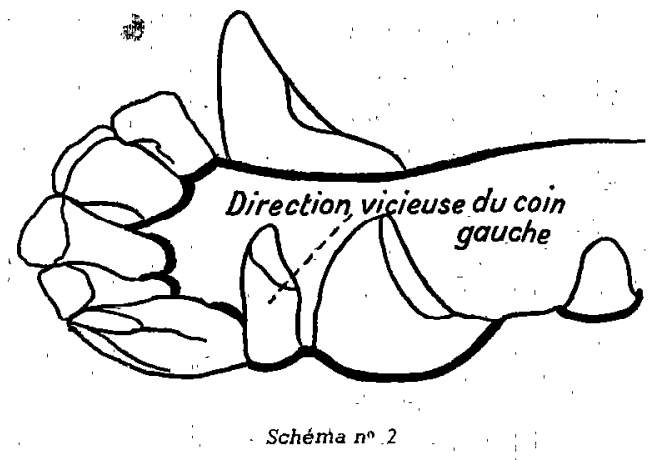

b) Anomalie d'implantation. - Une seule observation également : la pince gauche est implantée à l'intérieur de l'arcade dentaire. Par suite d'un diastème entre la mitoyenne et le coin droit, cottc mitoyenne vient occuper la place de la pince droite 
et celle-ci se situe a la place normale de la pince gauche; la mitoyenne gauche étant placée normalement, la pince gauche fait éruption à l'intérieur de l'arcade dentaire. Voir dessin $n^{\circ} 3$.

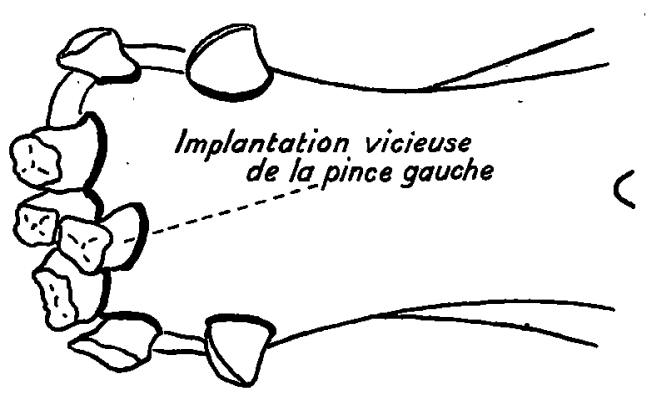

Schéma no 3

c) Anomalies de nombre. - Les variations numéraires peuvent être en plus ou en moins.

Dents surnuméraires. - Deux fois il fut observé une prémolaire caniniforme supplémentaire adjacente à la normale.

Absence de certaines dents. - Des prémolaires et des molaires peuvent manquer, La $2^{\circ}$ prémolaire inférieure manquait d'un seul côté trois fois; une fois, elle était absente de chaque arcade. L'absence des molaires n'a été observée que du côté droit. Au maxillaire supérieur, la $2^{\text {e }}$ molaire manque dans un cas; à l'inférieur, on a pu noter l'absence de la $1^{\text {re }}$ molaire deux fois, de la $2^{\text {c molaire }}$ une fois.

Nous ne considérons pas comme une anomalie l'absence d'une ou de plusieurs prémolaires caniniformes. La plus grande fantaisie présidait à leur éruption chez les animaux examinés en provenance du Sud oranais. Faut-il voir là une evolution tendan à la disparition de ces dents? C'est notre avis. Le Commandant Cauvet pourrait y voir une interpénétration de ses deux types de dromadaires : l'arabe et l'africain, ces prémolaires pouvant manquer chez les animaux du type africain. Mais l'existence de ce type africain n'est pas démontrée. Selon Cauvet, le dromadaire « africain » aurait deux prémolaires sériées au maxillaire inférieur, mais n'est-ce pas là la mauvaise interprétation d'une donnée morphologique. En effet, nous avons remarqué souvent que par suite d'un articulé molaire défectueux, la $1^{\text {re }}$ molaire se divisait par l'usure en deux simulant ainsi une dent supplementaire; mais, par la coupe, on voit qu'il ne s'agit là que d'une même dent. Voir dessin no 4.

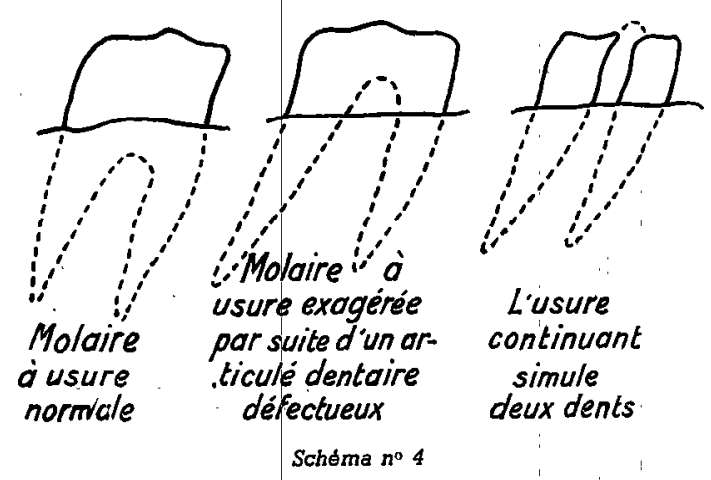

\title{
Observations sur l'emploi du vaccin de culture anti-péripneumonique en milieu sain et contaminé
}

\author{
par R. LARRAT
}

LAA péripneumonie fut introduite dans le troupeau du centre sérumigène de Makhana par un lot d'animaux réceptionnés dans la première quinzaine de Septembre 1943.

A partir de ce moment la maladie évolue jusqu'en Octobre 1944 lentement, irrégulièrement, avec deux poussées brutales (Janvier-Février et JuilletAoût) et une période silencieuse (Mai).

Ia totalité du troupeau contaminé fut isolée et nous avons pu suivre le comportement des animaux vaccinés avant et après la période de contamination.

La dose de culture-vaccin utilisée fut pour tous les animaux de 2 centimetres cubes.
Voir page suivante, dans le tableau, les observations qui ont été faites :

Commentaire. - La date de contamination possible est le ler Septembre 1943. Ce qui réduit singulièrement le délai de protection conférée par le virus-vaccin; il ne dépasse guère 250 jours et, tout au moins dans un cas, est inférieur à 198 jours.

On peut toutefois considérer que le producteur $79 \mathrm{~B}$, exposé à la contagion 32 jours après la vaccination, était encore en état de réceptivité (compte tenu des délais nécessaires pour la création de l'immunité).

Il n'en va pas de meme du $107 \mathrm{D}$. Le délai de 67 jours entre la vaccination et la mort doit etre évidemment réduit de la durée des periodes d'incubation et d'évolution.

La contamination étant possible à compter du ler Septembre 1943, dans le cas le plus extrême la protection conférée par le vaccin n'a pas dépassé 103 jours. 